\title{
High-resolution Impedance Manometry Criteria in the Sitting Position Indicative of Incomplete Bolus Clearance
}

Eui Ju Park, Joon Seong Lee, ${ }^{*}$ Tae Hee Lee, Gene Hyun Bok, Su Jin Hong, Hyun Gun Kim, Seong Ran Jeon and Jin-Oh Kim

Institute for Digestive Research, Digestive Disease Center, Department of Internal Medicine, Soonchunhyang University College of Medicine, Seoul, Korea

\section{Background/Aims}

We used high-resolution impedance manometry (HRIM) to determine the length of breaks on the isobaric contour which would predict incomplete bolus clearance in patients in the sitting position.

\section{Methods}

In total, 651 swallows in 71 patients with esophageal symptoms were studied using a solid-state HRIM system in the sitting position. Each swallow was classified as complete or incomplete bolus clearance by impedance criteria and peristaltic integrity was evaluated using 20- and $30-\mathrm{mmHg}$ pressure topography isobaric contours. Correlations between the lengths of the breaks for 20 - and $30-\mathrm{mmHg}$ were analyzed.

\section{Results}

Complete bolus clearance was observed in $83.3 \%(542 / 651)$ of swallows. Breaks of 3 and $7 \mathrm{~cm}$ or less were associated with a bolus clearance of $96.8 \%$ on the $20-\mathrm{mmHg}$ and $94.7 \%$ on the $30-\mathrm{mmHg}$ isobaric contour, respectively $(P<0.001)$. The areas under the ROC curves for the 20 and $30 \mathrm{mmHg}$ isobaric contours were 0.900 and 0.950 , respectively. The sensitivity and specificity for complete bolus clearance were $75.6 \%$ and $89.3 \%$ for breaks $3 \mathrm{~cm}$ or less on the $20-\mathrm{mmHg}$ isobaric contour and $87.9 \%$ and $78.7 \%$ for breaks $7 \mathrm{~cm}$ or less on the $30-\mathrm{mmHg}$ contour $(P<0.001)$.

\section{Conclusions}

Breaks of $<3 \mathrm{~cm}$ in the $20-\mathrm{mmHg}$ isobaric contour or $<7 \mathrm{~cm}$ in the $30-\mathrm{mmHg}$ isobaric contour were associated with complete bolus clearance. The threshold for breaks in the sitting position was greater than previous reports using the supine position and longer breaks predicted incomplete bolus clearance.

(J Neurogastroenterol Motil 2014;20:491-496)

\section{Key Words}

High-resolution impedance manometry; Incomplete bolus clearance; Sitting position

Received: February 11, 2014 Revised: May 2, 2014 Accepted: May 22, 2014

(c) This is an Open Access article distributed under the terms of the Creative Commons Attribution Non-Commercial License (http://creativecommons. org/licenses/by-nc/3.0) which permits unrestricted non-commercial use, distribution, and reproduction in any medium, provided the original work is properly cited.

*Correspondence: Joon Seong Lee, MD, PhD

Institute for Digestive Research and Digestive Disease Center, Soonchunhyang University Hospital, 59, Daesagwan-ro, Younsan-gu, Seoul 140-743, Korea

Tel: +82-2-709-9202, Fax: +82-2-709-9696, E-mail: drjslee@dreamwiz.com

Financial support: This study was supported in part by the Soonchunhyang University Research Fund (Dr Joon Seong Lee).

Author contributions: Eui Ju Park contributed to analysis and interpretation of data and drafted the manuscript; Joon Seong Lee designed and coordinated the study, contributed to data interpretation and edited manuscript; Tae Hee Lee and Gene Hyun Bok contributed to the acquisition of data and statististical analysis; Su Jin Hong, Hyun Gun Kim, Seong Ran Jeon and Jin-Oh Kim performed critical revision of manuscript.

ORCID: Eui Ju Park, http://orcid.org/0000-0003-2934-0335; Joon Seong Lee, http://orcid.org/ 0000-0002-9616-3028; Tae Hee Lee, http://orcid.org/0000-0003-3049-8252.

Conflicts of interest: None. 


\section{Introduction}

The primary function of the esophagus is the effective transport of a bolus from the oral cavity into the stomach, requiring the timed coordination of circular and longitudinal muscle contractions. Transport is successful when minimal bolus material is retained within the esophageal body. Traditionally, videofluoroscopy has been the gold standard for examining esophageal bolus transit, ${ }^{1,2}$ while more recently multichannel impedance monitoring, combined with manometry, has been introduced to measure bolus transit by detecting changes in resistance to current flow when a bolus traverses an electrode pair. ${ }^{3,4}$ Several investigators have studied the predictive value of combined impedance and manometry for bolus transit. Tutuian and Castell ${ }^{5}$ demonstrated that a peristaltic amplitude of $\geq 30 \mathrm{mmHg}$ predicted complete bolus transit in $95 \%$ of cases. However, a peristaltic amplitude of $<30 \mathrm{mmHg}$ was less predictive (52\%) and was not able to reliably detect incomplete bolus transit.

With the introduction of high-resolution manometry (HRM), spatial visualization of esophageal contractility by isocoloric regions on pressure topography plots has allowed more accurate prediction of bolus transit versus conventional manometry. Recently, Bulsiewicz et $\mathrm{al}^{6}$ used HRM to determine pressure topography thresholds of peristaltic integrity predictive of incomplete esophageal bolus clearance. They showed that in patients with normal esophagogastric junction (EGJ) relaxation and morphology, peristaltic contractions with breaks of $<2 \mathrm{~cm}$ in the $20-\mathrm{mmHg}$ isobaric contour or $<3 \mathrm{~cm}$ in the $30-\mathrm{mmHg}$ isobaric contour were associated with complete bolus clearance and longer breaks predicted incomplete bolus clearance. However, the studies using HRM were performed in the supine position, in contrast to nor-

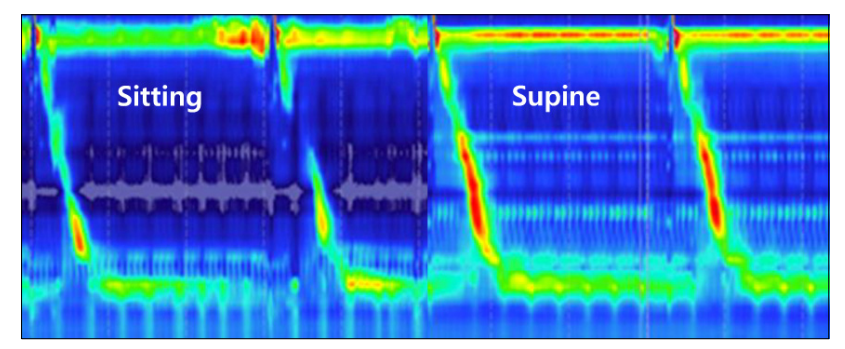

Figure 1. High-resolution manometry (HRM) of subjects according to body position. This shows an example of how body position can affect HRM results in healthy adults. Peristaltic wave amplitude and distal contractile integral decreased significantly and more frequent weak and absent peristalsis were seen in the sitting position. mal behavior. Previous reports have shown that body position has significant effects on HRM results. ${ }^{7-10}$ Specifically, wave amplitude, duration and distal contractile integral have been reported to decrease in the sitting position compared with the supine position. ${ }^{9}$ A peristalsis and hypoperistalsis were also observed more frequently in the sitting position (Fig. 1). The aim of this study was to determine the length of breaks on the isobaric contour which would predict incomplete bolus clearance in patients in the sitting position using high-resolution impedance manometry (HRIM).

\section{Materials and Methods}

\section{Patients}

HRIM studies were performed on consecutive patients with at least one of the following symptoms: dysphagia, heartburn, regurgitation, non-cardiac chest pain, globus and odynophagia. For each symptom, the patients were asked to rate the frequency and severity on a 5 -point Likert scale (frequency: $0=$ never, $1=$ less than once/month, 2 = 1-4 times/month, $3=$ once and more/week and $4=$ daily; and severity: $0=$ none, $1=$ mild, $2=$ moderate, 3 $=$ severe and $4=$ very severe). Patients were excluded if they had an abnormal esophageal anatomy, impaired EGJ relaxation or a hiatal hernia by HRIM criteria. The study was approved by Soonchunhyang University Hospital Institutional Review Board.

\section{High-resolution Impedance Manometry Protocol}

Manometric and impedance data were obtained using a combined solid-state manometry and impedance assembly with 36 circumferential sensors spaced at $1 \mathrm{~cm}$ intervals (Sierra Scientific Instruments Inc., Los Angeles, CA, USA) and 8 impedance sensors spaced at $5 \mathrm{~cm}$ intervals. After fasting for a minimum of 6 hours, patients underwent a short interview and completed symptom-related questionnaires. All medications that might affect gastrointestinal motility were discontinued for at least 72 hours. The HRIM assembly probe was inserted trans-nasally with the patient in a sitting position. The assembly was placed to record manometric data from the hypopharynx to the stomach, using at least 3 intragastric sensors. The impedance sensors were positioned to record from the beginning of the proximal esophageal segment through the distal esophagus and into the proximal stomach with at least 1 intragastric impedance measurement. The assembly was fixed in place by taping it to the nose. The manometric protocol included 30 seconds without swallows to assess basal EGJ pressure 
and morphology followed by $10-15$ swallows of $5 \mathrm{~mL}, 0.3 \%$ saline solution in the patient in the sitting position. ${ }^{6}$

\section{Data Analysis}

HRIM data were analyzed using the ManoView software (ver. 2.0; Sierra Scientific Instruments Inc.) by one investigator who was blinded to the diagnosis and symptoms. Only swallows spaced at $\geq 20$ seconds were included, and double swallows or swallows including cough-induced pressure artifacts were excluded from the analysis. Isobaric contour plots were overlaid with impedance line tracings, providing concurrent visualization of pressure and impedance data. Lower esophageal sphincter (LES) residual pressure in the sitting position was assessed using the 3 -second nadir and a resting pressure greater than $11 \mathrm{mmHg}$ was considered abnormal. ${ }^{11}$ If the mean deglutitive LES relaxation pressure was $>11 \mathrm{mmHg}$, then the patient was considered to have impaired EGJ relaxation and was excluded from the study. The integrity of esophageal peristalsis was assessed using the isobaric contour tool. Any disruption in the peristaltic wave, including the proximal, transitional and distal contractile segments, was considered a break. The vertical length of each break in the isobaric contour was measured using the smart mouse function (Fig. 2). Swallows were then stratified according to the length of longest break in $1 \mathrm{~cm}$ increments: (1) no break, (2) $\leq 1 \mathrm{~cm}$, (3) $1<$ and $\leq 2 \mathrm{~cm}$ (4) $2<$ and $\leq 3 \mathrm{~cm}$, and so on. Each swallow was assessed twice, for the 20- and 30-mmHg isobaric contours.

Bolus transit was assessed for each swallow using the impedance line tracings. Bolus entry was defined as $\geq 50 \%$ decrease in impedance with respect to baseline. ${ }^{12-14}$ Bolus clearance was de-

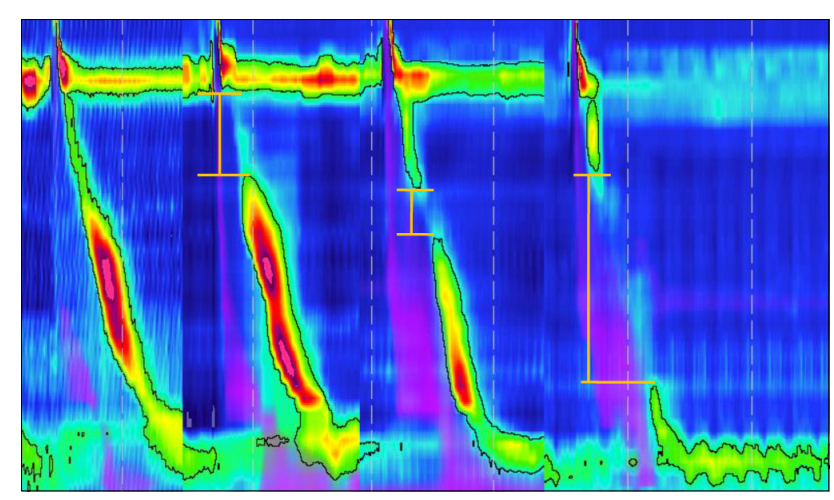

Figure 2. Analysis of peristaltic integrity in esophageal pressure topography. In this example, the isobaric contour of $20 \mathrm{mmHg}$ was analyzed. The smart mouse function was used to measure the vertical length between the proximal and distal margins of each break in the isobaric contour. fined as sustained ( $>5$ seconds) $\geq 50 \%$ increase in impedance from the original baseline impedance. ${ }^{15}$ Complete bolus clearance was defined as bolus entry followed by bolus clearance at all impedance recording sites, and incomplete bolus clearance was defined as bolus entry followed by failure of bolus clearance at any of the impedance recording sites. According to these definitions, each swallow was classified as having complete or incomplete bolus clearance. Patients were defined as having abnormal bolus transit when $\geq 30 \%$ of swallows had incomplete bolus clearance. ${ }^{16}$

\section{Statistical Methods}

Statistical analyses were performed using the SPSS software (version 18.0; SPSS, Chicago, IL, USA). Linear-by-linear association was used to identify correlations between bolus clearance and the length of breaks for the 20- and 30-mmHg isobaric contours. A difference was considered statistically significant when the $P$-value was $<0.05$. A receiver operating characteristic $(\mathrm{ROC})$ curve was constructed by plotting sensitivity versus 100 -specificity to evaluate the length of breaks needed to accurately predict bolus clearance. The reporting of this study was conducted in accordance with the Standards for Reporting of Diagnostic Accuracy guidelines.

\section{Results}

\section{Baseline Characteristics of Patients}

In total, 97 consecutive patients were studied. Of them, 26 were excluded: 17 with achalasia, 5 with mean deglutitive LES relaxation pressures $>11 \mathrm{mmHg}, 1$ with a history of an Ivor-Lewis operation for esophageal cancer and 1 patient with scleroderma. In total, 652 swallows from 71 patients were included in the final data analysis. Table illustrates the general and clinical characteristics of the patients. There were 31 males $(43.7 \%)$ and the mean age of the patients was 53 (range, 18-85) years. Major symptoms were dysphagia (19.7\%), heartburn (12.7\%), regurgitation (18.3\%), non-cardiac chest pain $(19.7 \%)$, globus $(28.2 \%)$ and odynophagia (1.4\%). Symptom scores of the patients (Likert scale) were estimated according to frequency and severity. Globus was the most common presenting symptom $(50.7 \%)$ with a high frequency and severity score.

\section{Correlation Between Length of Breaks in Isobaric Contour and Bolus Transit}

In total, 651 individual swallows were analyzed. Complete bolus clearance was observed in 542 (83.3\%) swallows. On 20$\mathrm{mmHg}$ isobaric contours, only 6 of 285 (2.1\%) swallows with 
Table. Baseline Patient Characteristics and Symptom Scores (Likert Scale)

\begin{tabular}{|c|c|c|c|c|}
\hline Characteristics & & & & \\
\hline Patient (n) & & 71 & & \\
\hline Male (n [\%]) & & $31(43.7)$ & & \\
\hline Age (median age [range], yr) & & $53(18-85)$ & & \\
\hline \multirow{2}{*}{ Symptoms } & \multirow{2}{*}{$\begin{array}{l}\text { Major symptoms } \\
\quad \text { (n [\%]) }\end{array}$} & \multirow{2}{*}{$\begin{array}{l}\text { Presenting symptoms } \\
\text { (n [\%]) }\end{array}$} & \multicolumn{2}{|c|}{ Likert scale } \\
\hline & & & Frequency & Severity \\
\hline Dysphagia & $14(19.7)$ & $22(31.0)$ & 1.03 & 0.82 \\
\hline Heartburn & $9(12.7)$ & $18(25.3)$ & 0.77 & 0.66 \\
\hline Regurgitation & $13(18.3)$ & $35(49.3)$ & 1.31 & 1.10 \\
\hline Non-cardiac chest pain & $14(19.7)$ & $29(40.8)$ & 1.18 & 1.31 \\
\hline Globus & $20(28.2)$ & $36(50.7)$ & 1.69 & 1.39 \\
\hline Odynophagia & $1(1.4)$ & $2(2.8)$ & 0.06 & 0.06 \\
\hline
\end{tabular}

breaks of $1 \mathrm{~cm}$ or less and 13 of 401 (3.2\%) swallows with breaks of $3 \mathrm{~cm}$ or less showed incomplete bolus clearance. However, as the length of the breaks increased, the rate of incomplete bolus clearance increased significantly $(P<0.001)$. Despite this, even significant breaks, over $8 \mathrm{~cm}$, showed complete bolus clearance in 20 of $92(21.7 \%)$ swallows. Complete bolus clearance was observed in 5 out of 53 swallows devoid of a distal contractile segment. On the $30-\mathrm{mmHg}$ isobaric contour, only 6 of 309 (1.9\%) swallows with breaks of $3 \mathrm{~cm}$ or less, and 26 of 491 (5.3\%) swallows with breaks of $7 \mathrm{~cm}$ or less showed incomplete bolus clearance. On the $20-\mathrm{mmHg}$ isobaric contour, the rate of incomplete bolus clearance increased with the length of the break $(P<0.001)$. Short breaks in the isobaric contour of 3 and $7 \mathrm{~cm}$ or less were associated with bolus clearance of $96.8 \%$ on the $20-\mathrm{mmHg}$ and $94.7 \%$ on the $30-\mathrm{mmHg}$ isobaric contour, respectively $(P<0.001)$.

\section{Isobaric Contour and Breaks Associated With Incomplete and Complete Bolus Clearance}

In the isobaric $20-\mathrm{mmHg}$ contour, the median (interquartile range) length of the break of incomplete bolus clearance was 10 $(5-17) \mathrm{cm}$ and that of complete clearance was $1(0-3) \mathrm{cm}(P<$ 0.001 ). In the isobaric $30-\mathrm{mmHg}$ contour, the median (interquartile range) length of the break of incomplete bolus clearance was $13.5(8-19) \mathrm{cm}$ and that of complete clearance was $3(1-6) \mathrm{cm}$ $(P<0.001)$.

\section{Isobaric Contour Breaks Predictive of Bolus Clearance in Individual Swallows}

ROC curves were constructed for both the 20 - and $30-\mathrm{mmHg}$ isobaric contours. On the $20-\mathrm{mmHg}$ isobaric contour, breaks of 3 $\mathrm{cm}$ or less had a sensitivity and specificity of $75.6 \%$ and $89.3 \%$, re- spectively, for predicting complete bolus clearance (95\% CI, 71.7-79.2). The area under the curve (AUC) was 0.900 (95\% CI, 0.87-0.92; Fig. 3A). On the 30-mmHg isobaric contour, breaks of $7 \mathrm{~cm}$ or less had a sensitivity and specificity of $87.9 \%$ and $78.7 \%$, respectively, for predicting complete bolus clearance $(95 \%$ $\mathrm{CI}, 84.8-90.6)$. The AUC on the $30-\mathrm{mmHg}$ isobaric contour was 0.905 (95\% CI, 88.0-92.7; Fig. 3B). There was no significant difference between the ROC curves for the 20 - and $30-\mathrm{mmHg}$ isobaric contours (Fig. 3C).

\section{Discussion}

In this study, we used a solid-state HRIM system to investigate the characteristics of defects in the peristaltic wave of individual swallows that are predictive of bolus clearance in patients in the sitting position. Previous studies performed in the supine position showed that greater defects were associated with increased incomplete bolus clearance. ${ }^{6}$ In this study, we demonstrated that breaks of $<3 \mathrm{~cm}$ in the $20-\mathrm{mmHg}$ isobaric contour or $<7 \mathrm{~cm}$ in the $30-\mathrm{mmHg}$ isobaric contour could significantly predict complete bolus clearance with the patient in the sitting position. However, the threshold for breaks in the sitting position was greater than previous reports in the supine position and complete bolus clearance was observed frequently in patients who would have been classified as having hypotensive or absent peristalsis, according to the Chicago HRM criteria.

These results indicate that body position affects the results of HRM. ${ }^{9}$ More specifically, the workload required for bolus transit is decreased in the sitting position, mainly because of gravity. Xiao et $\mathrm{al}^{11}$ demonstrated that normative value of integrated relaxation pressure decreased significantly in the sitting position compared to supine position because of the assistance of 

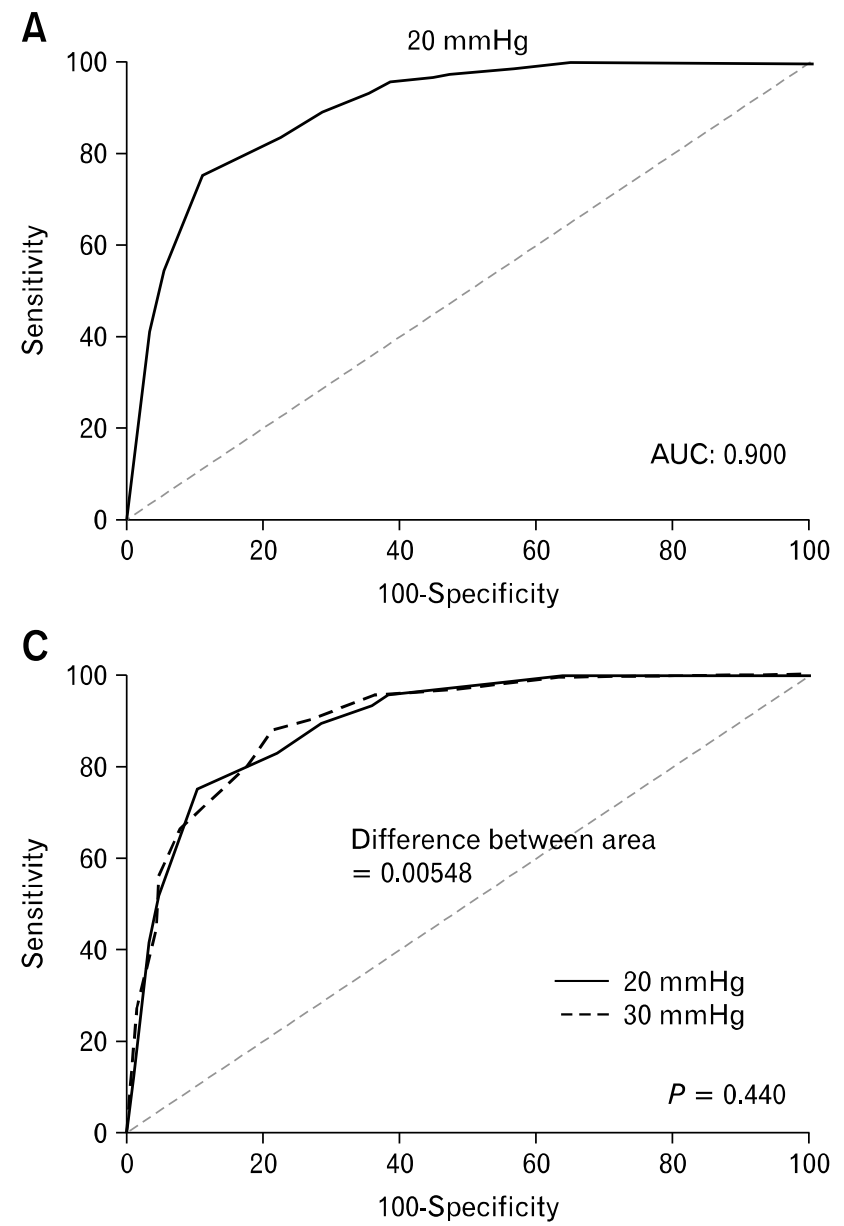

gravity and recommended a cutoff value of $11 \mathrm{mmHg}$ in the sitting position. Therefore we also applied cutoff value $(>11$ $\mathrm{mmHg}$ ) for the impaired EGJ relaxation in our data analysis. Several investigators have recognized the effects of body position on HRM results and have recommended performing studies in the physiological upright position and including solid swallows to increase sensitivity to symptomatic dysmotility and dysfunction. ${ }^{7,17,18}$ Because supine "normal" values cannot be applied to an upright or sitting position, normal values in the sitting position should be determined. However, there are few data regarding reference values for HRM in the sitting or upright position.

In the 20 - and $30-\mathrm{mmHg}$ isobaric contours, the mean length of the break for an incomplete bolus was higher than that for a complete one. Similar to another study, ${ }^{6}$ our data showed that longer breaks predicted incomplete bolus clearance.

In our study, there was no difference in the symptoms between complete and incomplete bolus transit. Also, symptoms and bolus transit were not associated with breaks of $3 \mathrm{~cm}$ in the $20-\mathrm{mmHg}$ isobaric contour or $7 \mathrm{~cm}$ in the $30-\mathrm{mmHg}$ isobaric

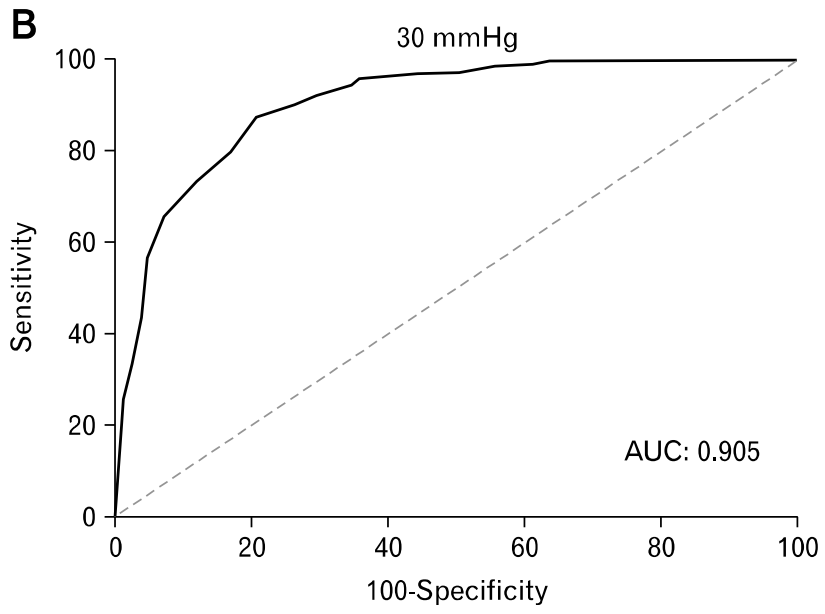

Figure 3. Isobaric contour breaks which are predictive of bolus clearance in individual swallows. Receiver operating characteristic (ROC) curves were prepared for the $20-\mathrm{mmHg}(\mathrm{A})$ and $30-\mathrm{mmHg}$ (B) isobaric contours. On the 20 - and $30-\mathrm{mmHg}$ isobaric contours, breaks of $3 \mathrm{~cm}$ or less and $7 \mathrm{~cm}$ or less had sensitivity and specificity for predicting complete bolus clearance, respectively. The areas under the curves (AUCs) on the 20- and $30-\mathrm{mmHg}$ isobaric contours were 0.900 and 0.905 , respectively. In the ROC curves for the 20 - and $30-\mathrm{mmHg}$ isobaric contours $(\mathrm{C})$, there was no difference between the ROC curves for the 20 - and $30-\mathrm{mmHg}$ isobaric contours $(P=$ $0.440)$. The solid line indicates the ROC based on chance alone and has a c-statistic of 0.5 .

contours. This suggests that symptoms may be caused by various other factors, such as the amount of esophageal wall distension and the sensitivity of the esophageal wall. ${ }^{19}$ The amount of esophageal wall distension will be affected by bolus transit, break, LES relaxation and regurgitation. These findings are similar to a previous study, where there was a poor correlation between dysphagia symptoms and esophageal dysmotility in terms of contractility and impaired bolus transport. ${ }^{20}$

Our study has several limitations. The major one is the retrospective study design. Symptoms were assessed by self-reported questionnaires; we did not evaluate symptoms according to individual swallowing. Our study did not include healthy adults but only the symptomatic patients. Several studies showed strong correlation between impedance measurements and videofluoroscopy in assessing bolus transit in healthy adults. ${ }^{14,21}$ Only one small study validated esophageal impedance method for bolus transit patterns in comparison with barium videoesophagram in 16 dysphagia patients, and still showed impedance monitoring as a valid transit test in dyspeptic patients with severe barium stasis. ${ }^{22}$ However, 
studies using concurrent manometric and videofluoroscopic recording in symptomatic patients showed an excellent correlation between the findings from 2 tests. ${ }^{23,24}$ It is known that bolus transit is affected by impaired LES, peristalsis and gravity. Thus, our study was investigated in symptomatic patients without impaired EGJ relaxation to overcome the limitations. In this study, our impedance data were recorded bisectionally as complete and incomplete bolus clearance. Although incomplete bolus clearance does not necessarily equate to failed bolus transit, observations from fluoroscopy suggested that defects of that length resulted in most if not all of the swallowed bolus being retained in the esophagus. ${ }^{6,23}$ However, the strength of the study includes that the pressure topography criteria indicative of complete bolus clearance were determined in the physiological situation, the sitting position.

In conclusion, breaks of $<3 \mathrm{~cm}$ in the $20-\mathrm{mmHg}$ isobaric contour or $<7 \mathrm{~cm}$ in the $30-\mathrm{mmHg}$ isobaric contour by highresolution esophageal manometry were associated with complete bolus clearance in the sitting position. The threshold for breaks in the sitting position was greater than in previous reports using the supine position and longer breaks predicted incomplete bolus clearance. Further studies and prospective approaches are needed to confirm these results.

\section{References}

1. Ferriolli E, Dantas RO, Oliveira RB, Braga FJ. The influence of ageing on oesophageal motility after ingestion of liquids with different viscosities. Eur J Gastroenterol Hepatol 1996;8:793-798.

2. Jou J, Radowsky J, Gangnon R, et al. Esophageal clearance patterns in normal older adults as documented with videofluoroscopic esophagram. Gastroenterol Res Pract 2009;2009:965062.

3. Kessing BF, Smout AJ, Bredenoord AJ. Clinical applications of esophageal impedance monitoring and high-resolution manometry. Curr Gastroenterol Rep 2012;14:197-205.

4. Burgess NG, Wyeth JW. An audit of combined multichannel intraluminal impedance manometry in the assessment of dysphagia. J Gastroenterol Hepatol 2011;26(suppl 3):79-82.

5. Tutuian R, Castell DO. Clarification of the esophageal function defect in patients with manometric ineffective esophageal motility: studies using combined impedance-manometry. Clin Gastroenterol Hepatol 2004;2:230-236.

6. Bulsiewicz WJ, Kahrilas PJ, Kwiatek MA, Ghosh SK, Meek A, Pandolfino JE. Esophageal pressure topography criteria indicative of incomplete bolus clearance: a study using high-resolution impedance manometry. Am J Gastroenterol 2009;104:2721-2728.

7. Bernhard A, Pohl D, Fried M, Castell DO, Tutuian R. Influence of bolus consistency and position on esophageal high-resolution manometry findings. Dig Dis Sci 2008;53:1198-1205.

8. Fox M, Menne D, Stutz B, Fried M, Schwizer W. The effects of tegaserod on oesophageal function and bolus transport in healthy vol- unteers: studies using concurrent high-resolution manometry and videofluoroscopy. Aliment Pharmacol Ther 2006;24:1017-1027.

9. Roman S, Damon H, Pellissier PE, Mion F. Does body position modify the results of oesophageal high resolution manometry? Neurogastroenterol Motil 2010;22:271-275.

10. Lee JS, Park MI, Moon W, et al. Is there any difference in the esophageal motor parameters of high resolution manometry between the supine and sitting positions? Korean J Neurogastroenterol Motil 2009;15:31-37.

11. Xiao Y, Read A, Nicodème F, Roman S, Kahrilas PJ, Pandolfino JE. The effect of a sitting vs supine posture on normative esophageal pressure topography metrics and Chicago classification diagnosis of esophageal motility disorders. Neurogastroenterol Motil 2012;24: e509-e516.

12. Tutuian R, Elton JP, Castell DO, Gideon RM, Castell JA, Katz PO. Effects of position on oesophageal function: studies using combined manometry and multichannel intraluminal impedance. Neurogastroenterol Motil 2003;15:63-67.

13. Tutuian R, Castell DO. Combined multichannel intraluminal impedance and manometry clarifies esophageal function abnormalities: study in 350 patients. Am J Gastroenterol 2004;99:1011-1019.

14. Simrén M, Silny J, Holloway R, Tack J, Janssens J, Sifrim D. Relevance of ineffective oesophageal motility during oesophageal acid clearance. Gut 2003;52:784-790.

15. Sifrim D, Castell D, Dent J, Kahrilas PJ. Gastro-oesophageal reflux monitoring: review and consensus report on detection and definitions of acid, non-acid, and gas reflux. Gut 2004;53:1024-1031.

16. Tutuian R, Vela MF, Balaji NS, et al. Esophageal function testing with combined multichannel intraluminal impedance and manometry: multicenter study in healthy volunteers. Clin Gastroenterol Hepatol 2003;1:174-182.

17. Sweis R, Anggiansah A, Wong T, Kaufman E, Obrecht S, Fox M. Normative values and inter-observer agreement for liquid and solid bolus swallows in upright and supine positions as assessed by esophageal high- resolution manometry. Neurogastroenterol Motil 2011; 23:509, e198.

18. Fox MR, Bredenoord AJ. Oesophageal high-resolution manometry: moving from research into clinical practice. Gut 2008;57:405-423.

19. Bohn B, Bonaz B, Gueddah N, et al. Oesophageal motor and sensitivity abnormalities in non-obstructive dysphagia. Eur J Gastroenterol Hepatol 2002;14:271-277.

20. Chen $\mathrm{CL}$, Yi CH. Clinical correlates of dysphagia to oesophageal dysmotility: studies using combined manometry and impedance. Neurogastroenterol Motil 2008;20:611-617.

21. Imam H, Shay S, Ali A, Baker M. Bolus transit patterns in healthy subjects: a study using simultaneous impedance monitoring, videoesophagram, and esophageal manometry. Am J Physiol Gastrointest Liver Physiol 2005;288:G1000-G1006.

22. Cho YK, Choi MG, Oh SN, et al. Comparison of bolus transit patterns identified by esophageal impedance to barium esophagram in patients with dysphagia. Dis Esophagus 2012;25:17-25.

23. Kahrilas PJ, Dodds WJ, Hogan WJ. Effect of peristaltic dysfunction on esophageal volume clearance. Gastroenterology 1988;94:73-80.

24. Drewes AM, Reddy H, Staahl C, et al. Sensory-motor responses to mechanical stimulation of the esophagus after sensitization with acid. World J Gastroenterol 2005;11:4367-4374. 